\title{
Factors affecting variation in the vase life response of waxflower cultivars (Myrtaceae: Chamelaucium Desf. and Verticordia spp. Desf.) tested under various vase solutions
}

\author{
Cao D. Dung ${ }^{1 *}$, Kevin Seaton ${ }^{2}$,Zora Singh ${ }^{3}$ \\ ${ }^{1}$ Potato, Vegetable and Flower Research Center \\ Thai phien village, Ward 12, Da Lat, Lam Dong, Vietnam \\ ${ }^{2}$ Department of Agriculture and Food, Western Australia \\ 3 Baron-Hay Court, South Perth, WA 6151, Australia \\ ${ }^{3}$ Department of Environment and Agriculture \\ Curtin University \\ Kent Street, Bentley, Perth, WA 6102, Australia
}

\begin{abstract}
The effects of genotype and vase solutions on the vase lives of waxflower cultivars were studied. The vase life of 16 cultivars derived from different genetic backgrounds showed a variation. The vase life of Chamelaucium uncinatum cultivars held in deionised water was generally the shortest, with four cultivars averaging 9.5 and 8.9 days for flowers and leaves while the vase lives of $C$. uncinatum $\times$ megalopetalum hybrids were on average 16.0 and 25.0 days for flowers and leaves, respectively. The hybrid 'Southern Stars' with C. uncinatum $\times$ Verticordia plumosa as parents had the longest flower vase life of 24.9 days, although another Verticordia $\times$ Chamelaucium had a 9.5-day flower vase life and other hybrids of the cultivars of C. uncinatum and Verticordia grandis Desf. ('WX73'), C. sp. Gingin Marchantii ('WX97') and C. floriferum ('Lady Stephanie') as a parent had intermediate to short vase lives of 11.4 to 15.5 days. The cultivars responded most to 8-hydroxyquniline sulphate (HQS) + sucrose or HQS + sucrose + silver thiosulphate (STS), being 1.5- to 1.6-folds higher than in deionized water. The cultivars showed a varied response to a vase solution of sucrose + HQS + STS, with which C. uncinatum vase life increased 1.9-fold compared to 1.7-fold for C. megalopetalum. Waxflowers were found to be susceptible to water stress, causing flowers to close and shortening vase life. On average for the 80 cultivar-vase solution combinations tested, flower vase life ended when the stems reached $75.5 \pm 5 \%$ fresh weigh. Longer vase life cultivars had a greater ability of maintaining a water balance at or above $75 \%$ for longer.
\end{abstract}

Key words: 8-hydroxyquniline sulphate, fresh weight, genotype, genetic variation, water balance, waxflowers

\section{INTRODUCTION}

The vase life of cut flowers is highly dependent on the inheritance or genotype of the cultivars (Kende 1993). The vase lives of 17 Anthurium andraeanum Hort. cultivars varied from 14.0 days for 'Evergreen' to 49.0 days for 'Cuba', which was mainly dependent on the ability of cultivars to maintain positive water balance of cut stems (Elibox and Umaharan 2010). The vase life of Gerbera jamesonii Hooker cultivars was also variable (Tesi 1978), with some flowers lasting only 8.9 days while other flowers of

\footnotetext{
*Corresponding author.

Tel.: +84914051004;

e-mail: caodinhdung2003@yahoo.com (C.D. Dung).
} 
the same clone lasted 16.0 days (Jong and Garretson 1985). Natural variation in the postharvest quality and organ retention of ornamental plants can often be related to differences in their response to ethylene sensitivity (Macnish et al. 2010), which for carnations (Dianthus caryophyllus L.) is heritable from their parents (Woltering et al. 1993, Onozaki et al. 2001). The benefits of sugar, HQS and STS in extending flower vase life and reducing flower abscission had been reported for many types of cut flowers including Anthurium andraeanum Hort. (Asrar 2012), Gladiolus spp. L. (Beura et al. 2011), Dendrobium spp. Swart (Dineshbabu et al. 2002), C. uncinatum (Joyce 1988, Seaton 2006b) and C. megalopectalum hybrid 'Bridal' and 'Albany Pearl' (Seaton 2005). Sugar provides carbohydrates as an energy source for flower respiration and reduces the induction of endogenous ethylene (Pun and Ichimura 2003) and also improves water balance (Halevy and Mayak 1974, Kuiper et al. 1995). HQS prevents the growth of microorganisms in xylem vessels maintaining water uptake and extending flower vase life (Asrar 2012). Combining HQS and sucrose increased the flower quality and vase life of gladiolus (Beura et al. 2011) and dendrobiums (Dineshbabu et al. 2002). STS has been used to reduce endogenous ethylene production, and consequently extended the vase life of waxflowers (Joyce 1993, Seaton 2005). STS also inhibits the microbial population, which causes the vascular occlusion of stems (Asrar 2012). Vase life response varied with the addition of sugar to vase solutions for 'Golden Light', an inter-generic hybrid obtained between Sandersonia aurantiaca Hook. and Littonia modesta Hook., and was not improved (Eason et al. 2001) while it had a positive effect on the parents' vase life (Morgan et al. 2000). The vase life response of Asiatic hybrid lilies (Lilium L.) to STS was also dependent on genotype (van der Meulen-Muisers et al. 1999). We hypothesised the degree of vase life response in different genotypes of waxflowers depending on the water balance ability of the stems with several vase solutions. The aim of this study was to determine the degree of waxflowers' vase life response depending on the types of genotype derived from Chamelaucium and Verticordia crosses and the preserving solution containing combinations of sucrose, HQS and STS.

\section{MATERIAL AND METHODS}

\section{Plant materials}

The flowering stems of 16 cultivars derived from four species and hybrids of Chamelaucium and three hybrids of Chamelaucium and Verticordia (Tab. 1 and Fig. 1) were harvested in the field from an average of five mature bushes (approximately fives year old) at Medina Research Station (32 $13^{\prime} 18^{\prime \prime} \mathrm{S}$, $\left.115^{\circ} 38^{\prime} 50^{\prime \prime} \mathrm{E}\right)$ of the Department of Agriculture and Food Western Australia (DAFWA). All source plants

Table 1. The 16 cultivars used in the genetic variation study, their parents, petal colour and flower diameter

\begin{tabular}{llcc}
\hline Cultivars & \multicolumn{1}{c}{ Parents } & Petal colour & $\begin{array}{c}\text { Flower diameter } \\
(\mathrm{cm})\end{array}$ \\
\hline Purple Pride & C. uncinatum & mid purple & $1.7 \pm 0.03$ \\
Mullering Brook & C. uncinatum & mid pink & $1.2 \pm 0.02$ \\
Monica's Blush & C. uncinatum & cream-white & $1.4 \pm 0.03$ \\
WX17 & C. uncinatum & cream-white & $1.8 \pm 0.02$ \\
WX87 & C. uncinatum $\times$ C. megalopetalum & cream-white & $1.9 \pm 0.02$ \\
Matilda & (C. uncinatum $\times$ C. uncinatum $) \times$ C. megalopetalum & white & $2.1 \pm 0.02$ \\
Bridal Pearl & C. megalopetalum $\times$ C. uncinatum & cream-white & $1.6 \pm 0.02$ \\
Denmark Pearl & C. megalopetalum $\times$ C. uncinatum & cream-white & $1.7 \pm 0.02$ \\
Laura Mae Pearl & C. megalopetalum $\times$ C. uncinatum & cream-white & $1.6 \pm 0.01$ \\
Crystal Pearl & C. megalopetalum $\times$ C. uncinatum & cream-white & $1.8 \pm 0.02$ \\
WX102 & C. megalopetalum $\times$ C. uncinatum & mid pink & $1.9 \pm 0.02$ \\
Jasper & C. uncinatum $\times$ Verticordia plumosa & light-mid pink & $0.75 \pm 0.01$ \\
Southern Stars & C. uncinatum $\times$ Verticordia plumosa & very-light pink & $0.65 \pm 0.01$ \\
WX73 & (C. uncinatum $\times$ Verticordia grandis $) \times$ Verticordia grandis & very light red & $1.9 \pm 0.01$ \\
WX97 & C. sp. Gingin $\times($ C. uncinatum $\times$ C. uncinatum $)$ & cream-white & $1.1 \pm 0.02$ \\
Lady Stephanie & C. floriferum $\times$ C. uncinatum & white-light pink & $1.2 \pm 0.01$ \\
\hline
\end{tabular}

Data are the mean \pm standard error $(n=10)$ for opened flowers with a nectariferous hypanthium 


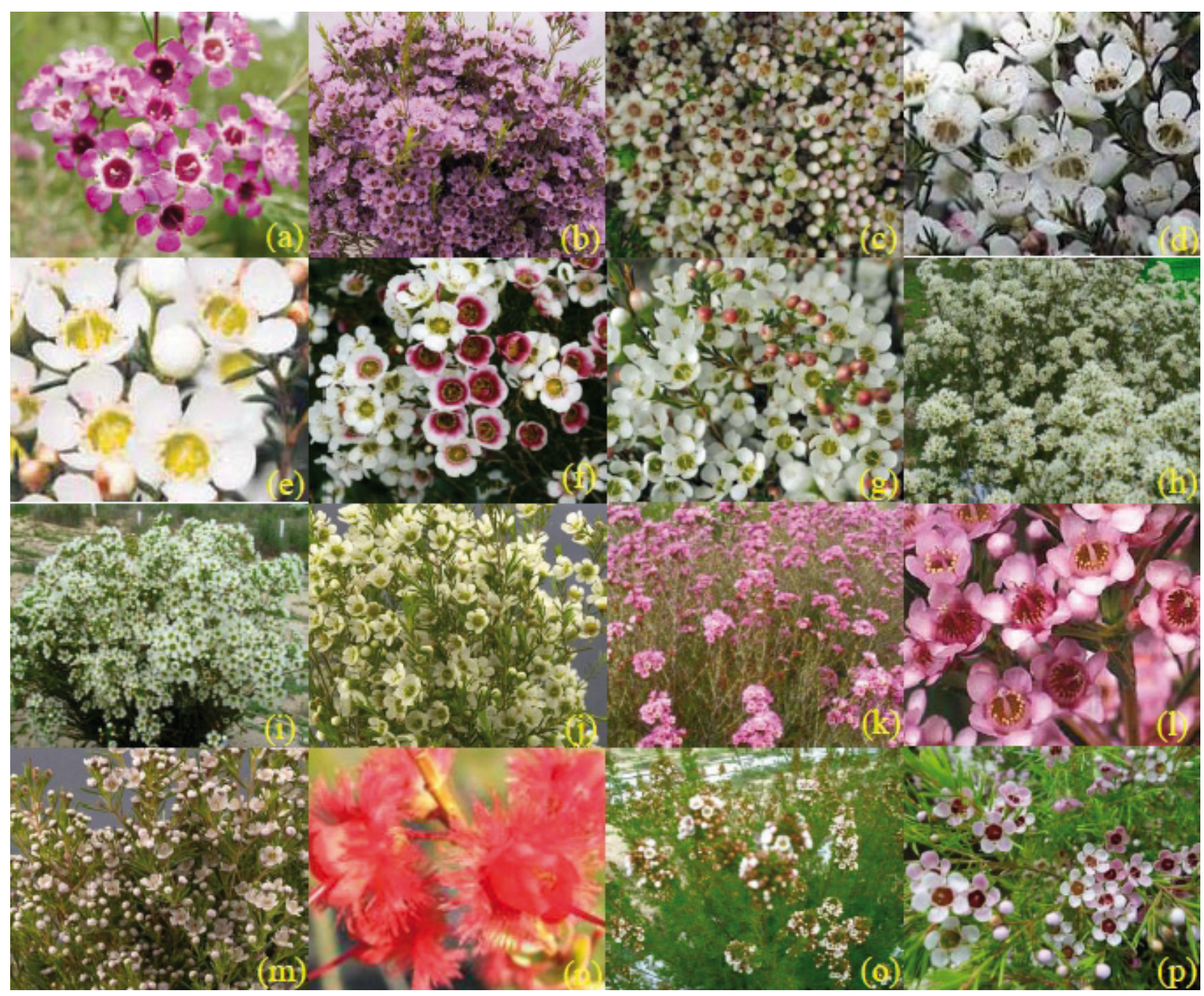

Figure 1. Waxflower cultivars used in the study: (a) Purple Pride, (b) Mullering Brook, (c) Monica's Blush, (d) WX17, (e) WX87, (f) Matilda, (g) Bridal Pearl, (h) Denmark Pearl, (i) Laura Mae Pearl, (j) Crystal Pearl, (k) WX102, (l) Jasper, (m) Southern Stars, (n) WX73, (o) WX97 and Lady Stephanie

were cultivated using irrigation and fertigation best practices (Seaton and Poulish 2010). Flowering stems of approximately $70 \mathrm{~cm}$ were picked with 50$70 \%$ flowers open in the early morning, and the cut ends of stems were immediately placed upright in buckets of clean water, and then transported by airconditioned vehicle at approximately $20^{\circ} \mathrm{C}$ to the postharvest laboratory of DAFWA at South Perth, taking about $35 \mathrm{~min}$. At the laboratory the cut stems were randomly chosen and recut under water to $30 \mathrm{~cm}$ in length (measured from the cut ends to the most extreme opened-flower) for vase life treatments (Seaton and Joyce 1996, Seaton et al. 2010).

\section{Vase solutions}

The following vase solutions were used to test the vase life response of waxflower cultivars:

1. Deionised water (DI) (control)

2. $200 \mathrm{mg} \mathrm{L}^{-1}$ 8-hydroxyquniline sulphate (HQS)
3. $200 \mathrm{mg} \mathrm{L}^{-1}$ 8-hydroxyquniline sulphate (HQS) and silver thiosultphate (STS) (applied as a 20-min pulse at $4 \mathrm{mM}$ )

4. $58.48 \mathrm{mmol}$ sucrose and $200 \mathrm{mg} \mathrm{L}^{-1}$ 8-hydroxyquniline (HQS)

5. $58.48 \mathrm{mmol}$ sucrose (sucrose) and 200 $\mathrm{mg} \mathrm{L}^{-1}$ 8-hydroxyquniline sulphate (HQS) and silver thiosultphate (STS) (applied as a 20 -min pulse at $4 \mathrm{mmol}$ ).

\section{Silver thiosulphate pulsing}

Harvested stems were recut under water at a length of $60 \mathrm{~cm}$, and then stood in a 4 mmol STS solution for $20 \mathrm{~min}$. at $20^{\circ} \mathrm{C}$. Immediately after pulsing, stem ends were rinsed under a running tap water and then stems stood with cut ends in buckets of clean water. Buckets containing pulsed-stems were placed in cold storage at approximately $5^{\circ} \mathrm{C}$ for $24 \mathrm{~h}$ in order to redistribute $\mathrm{Ag}^{+}$in the flower stems and then recut under water to $30 \mathrm{~cm}$ length for trials. 


\section{Assessment of vase life}

The end of flower vase life was recorded when $50 \%$ of the opened flowers fully closed or showed petal damage. For cultivars where flowers dropped before closing, the end of vase life was determined when $50 \%$ of the opened flowers had dropped. Leaf vase life was determined when $50 \%$ of the leaves were fully desiccated or yellow.

\section{Assessment of the relationship between flower vase life, stem fresh weight and days to stem fresh weight reaching $75 \%$ of initial weight}

Stem fresh weight was recorded daily until the end of flower vase life and expressed as a percentage of initial fresh weight. Analysing stem fresh weight at the end of flower vase life showed that flowers ended vase life when stem fresh weight reaching $75.5 \%$ of the initial weight. Thus, the day for stem fresh weight reaching $75 \%$ of initial weight was determined to analyse the relationship between flower vase life and the day for stem fresh weight at $75 \%$ of initial weight. Vase life was recorded in an air-conditioned room at $20 \pm 2^{\circ} \mathrm{C}, 60 \pm 10 \% \mathrm{RH}$ with a $12 \mathrm{~h}$ photoperiod. The light flux densities are $8 \mu \mathrm{m} \mathrm{m}^{-2} \mathrm{~s}^{-2}$.

\section{Statistical design and analysis}

The experiments were arranged in a completely randomized design with five treatments per cultivar, and each treatment was replicated eight times, excluding ' $\mathrm{WX} 73$ ' where the replication was five times. The vase life of the flowers and leaves from the treatments' effect was analysed by two-way ANOVA using the statistical package Genstat XV (Lawes Agricultural Trust, Rothamsted Experimental station, UK). Replication was eightfold consisting of a single stem in individual vases. Treatment means were compared by LSD at $\mathrm{p}=$ 0.05 and standard errors of the mean $( \pm \mathrm{SE})$ were shown as appropriate. When possible, mean comparisons were made using Duncan's Multiple Range Test.

\section{RESULTS}

\section{Effect of genotype in DI water}

There was a significant $(\mathrm{p}=0.05)$ difference in the vase life of flowers and leaves between cultivars ranging from 7.4 to 24.9 days for flowers and 5.5 and 21.5 days for leaves. The vase life of the cultivars of $C$. uncinatum was the shortest, at less than 12.0 days for flowers (ranging from 7.4 days for 'WX17' to 11.8 days for 'Mullering Brook') and less than 11.0 days for leaves (ranging from
5.5 days for 'WX17' to 11.0 days for 'Purple Pride'). For C. megalopetalum hybrids, vase life was longer than 12 days for flowers (ranging from 12.6 days for 'WX102' to 20.1 days for 'Crystal Pearl') and longer than 18.0 days for leaves (ranging from 18.1 days for 'WX87' to 31.0 days for 'Crystal Pearl'). Within the cultivars of $C$. uncinatum and C. megalopetalum, vase life was significantly higher for 'Crystal Pearl', 'Laura Mae Pearl' and 'Bridal Pearl', all of which had a vase life of 27.0 to 31.0 days, while the other C. uncinatum and C. megalopetalum of 'Denmark Pearl', 'Matilda', 'WX87' and 'WX102' had a 5.0 to 9.0 day shorter vase life. Similarly, the leaves of the C. megalopetalum hybrids 'WX87' and 'WX102' had a significantly $(\mathrm{p}=0.05)$ shorter vase life of 12.0 to 13.0 days compared to 'Crystal Pearl', 'Denmark Pearl', 'Laura Mae Pearl', 'Matilda' and 'Bridal Pearl', with 16.0 to 20.0 days vase life (Fig. 3). For three Verticordia hybrids, flower vase life showed a similar range to $C$. megalopetalum hybrids and ranged from 11.4 days for 'WX73', a C. uncinatum $\times V$. grandis hybrid, to 24.9 days for 'Southern Stars', a Chamelaucium $\times V$. plumosa hybrid, and the vase life of leaves ranged from 17.0 days for 'WX73' to 31.5 days for 'Southern Stars' (Figs 2 and 3). The Verticordia hybrid of 'Jasper' with a similar parentage as 'Southern Stars' in contrast had a flower vase life that was 10 days shorter than 'Southern Stars' and a leaf vase life that was not significantly $(p=0.05)$ different to 'Southern Stars'. However, vase life was longer for the C. floriferum hybrid 'Lady Stephanie' than the C. uncinatum cultivars, with 15.5 days for flowers and 18.5 days for leaves and flower vase life was 12.4 days for the C. sp. Gingin hybrid 'WX97', similar to the C. uncinatum cultivars, while leaf vase life was longer and similar to C. megalopetalum hybrids of 22.9 days.

\section{Effect of vase solutions - flower vase life}

Compared to DI water as a vase solution, sucrose, HQS and STS significantly $(\mathrm{p}=0.05)$ extended flower vase life over all of the cultivars by 1.6-fold, followed by the vase solution of sucrose and HQS by 1.5 -fold, whereas the vase solution of HQS and STS increased the vase life of cultivars by 1.2 -fold and the vase solution of HQS was less effective and caused the vase life of flowers to decrease in six cultivars (Fig. 2). A vase solution of sucrose, HQS and STS was more effective in C. uncinatum, increasing vase life 1.8 -fold compared to cultivars with $C$. megalopetalum as a parent (1.7-fold) and compared to cultivars with $C$. sp. Gingin (1.4-fold), 


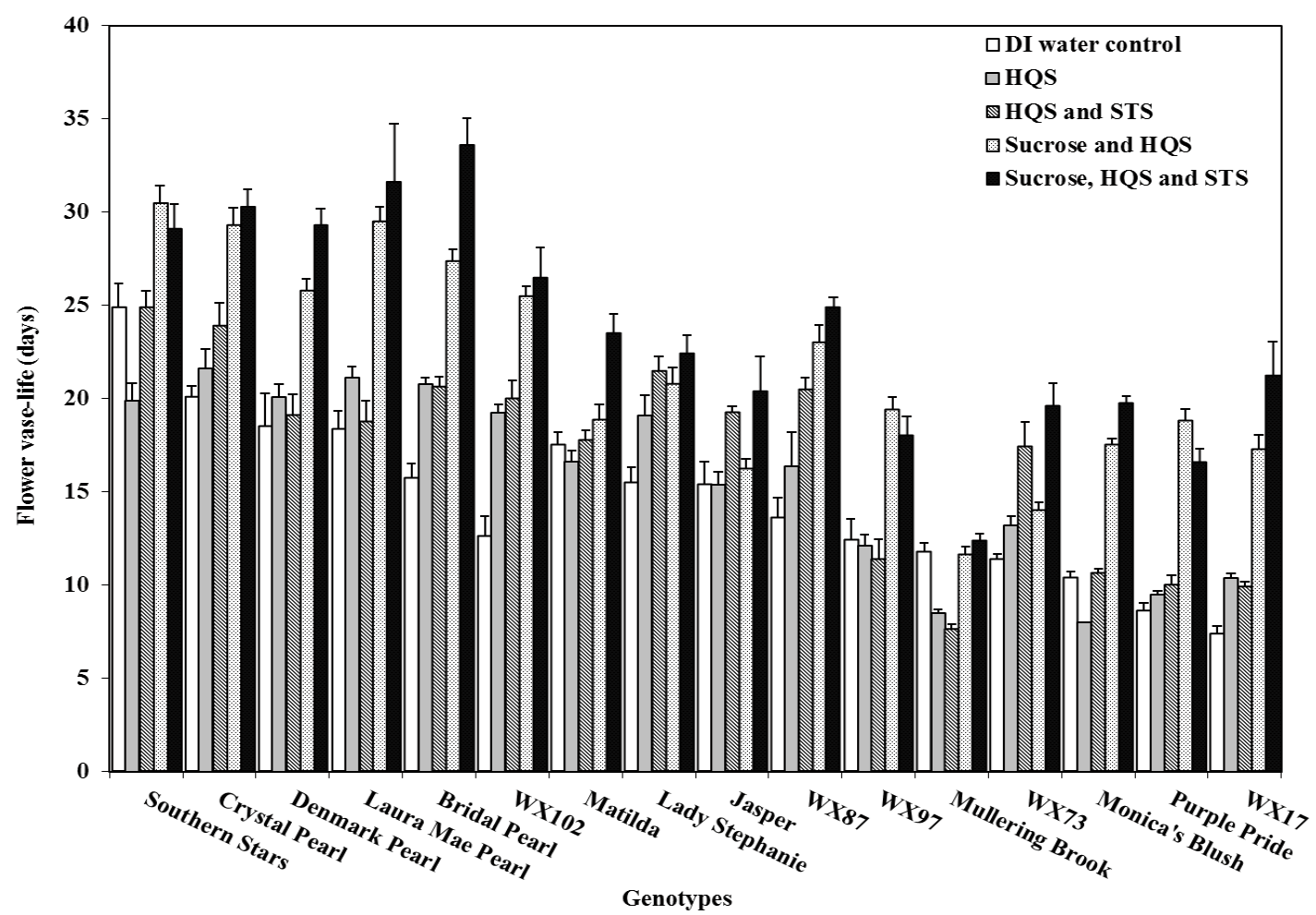

Figure 2. Vase life of flowers of cultivars held in various vase solutions and DI water as the control. LSD for genotype $=1.2$ days, for vase solution $=0.7$ day and for genotype $\times$ vase solution $=2.7$ days by two-way analysis of variance at $\mathrm{p}=0.05$. Vertical bars are standard errors of the mean

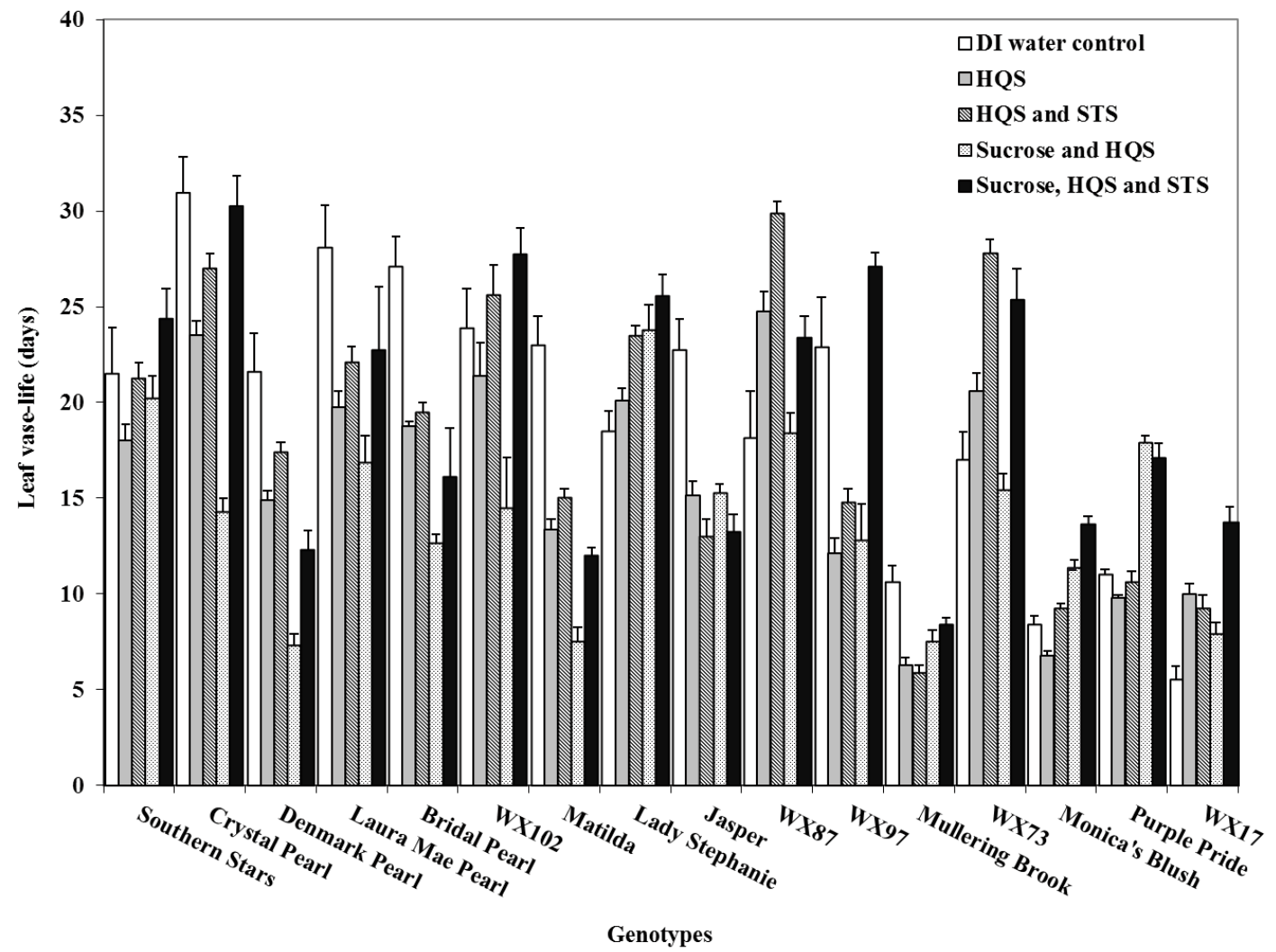

Figure 3. Leaf vase life of cultivars held in various vase solutions and DI water as the control. LSD for genotype $=1.5$ days, $\mathrm{LSD}$ for vase solution $=0.9$ day and LSD for genotype $\times$ vase solution $=3.4$ days by two-way analysis of variance at $p=0.05$. Vertical bars are standard errors of the mean 
C. floriferum (1.4-fold) or Verticordia (1.4-fold) as a parent. Cultivars with lower vase life tested in DI water had a larger response to vase solutions, with a flower vase life of 'WX17' increased by 2.9 -fold in sucrose, HQS and STS and similarly a 2.5 -fold increase in leaf vase life. 'Mullering Brook' was an exception and did not show a significant $(\mathrm{p}=0.05)$ response to sucrose, HQS and STS. The effect of vase solutions did not increase the vase life of the cultivar compared to the DI controls. The vase life of $C$. uncinatum cultivars was significantly ( $\mathrm{p}=$ 0.05 ) extended by 1.9 -fold in the vase solution of sucrose, HQS and STS and by 1.7-fold in the vase solution of sucrose and HQS, but did not increase in vase solutions of HQS or HQS and STS. The vase life of cultivars with $C$. megalopetalum as another parent was extended by 1.7- and 1.6-fold in vase solutions of sucrose and HQS with and without STS respectively, but by 1.2-fold in HQS or HQS and STS vase solutions (Fig. 2). The vase life of cultivars with Verticordia, C. sp. Gingin 'WX97' and C. floriferum 'Lady Stephanie' as another parent was significantly $(\mathrm{p}=0.05)$ extended by 1.4 -fold in the vase solution of sucrose, HQS and STS, while the vase solution of sucrose and HQS significantly ( $p=$ 0.05 ) extended the flower vase life of 'WX97' by 1.5fold, followed by the cultivars of 'Lady Stephanie' and cultivars with Verticordia as another parent by 1.3- and 1.2-fold, respectively. The vase solution of HQS and STS significantly $(\mathrm{p}=0.05)$ prolonged the vase life of 'Lady Stephanie' and cultivars with Verticordia as another parent by 1.4- and 1.3fold, respectively, but did not improve the vase life of 'WX97' compared to the DI controls. The vase solution of HQS also significantly $(p=0.05)$ prolonged the vase life of 'Lady Stephanie' by 1.2fold, but did not prolonged the vase life of 'WX97' or cultivars with Verticordia as another parent. The vase life of 'WX102' and 'WX17' was doubled in vase solutions of sucrose and HQS with or without STS, but had a 1.5-fold increase in vase solutions of HQS or HQS and STS compared to the DI controls. Similarly, the vase life of 'Purple Pride' doubled in vase solutions of sucrose and HQS or sucrose, HQS and STS, but vase life in HQS or HQS and STS vase solutions was not significantly $(p=0.05)$ different to those in the DI controls. The vase life of 'Jasper' and 'WX73' in the vase solution containing sucrose, HQS and STS was not significantly $(\mathrm{p}=0.05)$ different from those in vase solution of HQS and STS, but was longer with a 1.3- and 1.4-fold increase than those in the vase solution of sucrose and HQS (Fig. 2).

\section{Effect of vase solutions - leaf vase life}

Leaf vase life for all cultivars in the vase solution of sucrose, HQS and STS did not significantly $(\mathrm{p}=$ 0.05 ) differ to leaf vase life in vase solution of HQS and STS or the DI controls, but was significantly $(p=0.05)$ longer with a 1.2 - or 1.4-fold increase than the leaf vase life of HQS or sucrose and HQS vase solutions (Fig. 3). The leaf vase life of most cultivars except for 'Lady Stephanie', 'WX73' and 'WX17' decreased in vase solution of HQS compared to the DI controls. The leaf vase life of C. uncinatum cultivars was significantly $(\mathrm{p}=0.05)$ improved by 1.6 -fold in vase solutions of sucrose, HQS and STS, and by 1.2-fold in vase solution of sucrose and HQS, but did not increase in vase solutions of HQS or HQS and STS compared to the DI controls. The vase life of cultivars with C. megalopetalum as another parent, except for 'WX102', in vase solution of HQS and STS was significantly $(p=0.05)$ shorter than vase life in the DI water, which was significantly $(p=0.05)$ greater with a 1.3-fold increase than that of vase solutions of HQS or sucrose, HQS and STS and with a 2.0-fold increase over vase life in a vase solution of sucrose and HQS. The vase life of cultivar Southern Stars in DI water was similar to that of other vase solutions while the vase life of 'WX73' in DI water was similar to that of sucrose and HQS but significantly $(p=0.05)$ shorter than the vase life in vase solutions of HQS or HQS and STS or sucrose and HQS and STS. On the other hand, the vase life of 'Jasper' in DI water was significantly $(p=0.05)$ longer than that of other solutions. The vase life of 'WX97' was significantly $(p=0.05)$ longer, with a 1.2 -fold increase in vase solutions of sucrose, HQS and STS, but it decreased by half in the remaining vase solutions compared to the DI controls. Alternatively, the vase life of 'Lady Stephanie' was significantly $(p=0.05)$ longer with a 1.4-fold increase in vase solutions of sucrose, HQS and STS and 1.3-fold in vase solutions of sucrose and HQS or HQS and STS compared to the DI control, which was similar to the vase solution of HQS in increasing vase life (Fig. 3). The vase life of 'Monica's Blush' and 'Purple Pride' was significantly $(\mathrm{p}=0.05)$ longer, with a 1.6-fold increase, than vase life in the DI controls or vase solutions of HQS or HQS and STS. The vase life of 'WX17' in sucrose and HQS and STS was significantly $(\mathrm{p}=0.05)$ longer, with a 2.5-fold increase over vase life in the DI controls and with a 1.8-fold increase over vase life in the vase solution of sucrose and HQS. Compared to the DI control, the vase solution of HQS and STS 
Table 2. Percentage of stem fresh weight at the end of flower vase life in vase solutions

\begin{tabular}{lcccccc}
\hline Cultivars & Control & HQS & HQS and STS & $\begin{array}{c}\text { Sucrose and } \\
\text { HQS }\end{array}$ & $\begin{array}{c}\text { Sucrose, HQS } \\
\text { and STS }\end{array}$ & $\begin{array}{c}\text { Average fresh } \\
\text { weight }\end{array}$ \\
\hline Purple Pride & $67.4 \pm 1.5$ & $42.7 \pm 3.0$ & $63.5 \pm 6.0$ & $72.8 \pm 9.1$ & $74.0 \pm 3.9$ & $64.1 \pm 4.7$ \\
Mullering Brook & $86.9 \pm 5.4$ & $57.7 \pm 4.2$ & $61.1 \pm 8.4$ & $66.4 \pm 4.2$ & $78.3 \pm 2.6$ & $70.1 \pm 5.0$ \\
Monica's Blush & $77.7 \pm 2.7$ & $70.5 \pm 2.8$ & $68.4 \pm 2.8$ & $64.7 \pm 3.3$ & $84.9 \pm 3.3$ & $73.2 \pm 3.0$ \\
WX17 & $73.3 \pm 5.0$ & $76.2 \pm 1.7$ & $78.6 \pm 5.3$ & $74.6 \pm 6.4$ & $95.4 \pm 1.9$ & $79.6 \pm 4.1$ \\
WX87 & $68.4 \pm 5.4$ & $69.8 \pm 8.5$ & $81.7 \pm 2.1$ & $65.1 \pm 13.2$ & $91.0 \pm 7.0$ & $75.2 \pm 7.2$ \\
Matilda & $79.5 \pm 5.6$ & $63.8 \pm 4.3$ & $78.1 \pm 2.9$ & $48.8 \pm 4.8$ & $70.7 \pm 3.7$ & $68.2 \pm 4.3$ \\
Bridal Pearl & $87.0 \pm 3.1$ & $74.5 \pm 2.5$ & $83.3 \pm 0.6$ & $89.3 \pm 1.4$ & $92.7 \pm 5.5$ & $85.4 \pm 2.6$ \\
Denmark Pearl & $79.3 \pm 4.8$ & $51.5 \pm 7.7$ & $90.4 \pm 2.2$ & $56.4 \pm 11.8$ & $66.1 \pm 4.4$ & $68.7 \pm 6.2$ \\
Laura Mae Pearl & $82.9 \pm 3.6$ & $86.3 \pm 2.0$ & $92.2 \pm 3.2$ & $105.1 \pm 1.9$ & $98.4 \pm 9.6$ & $93.0 \pm 4.1$ \\
Chrystal Pearl & $69.4 \pm 2.8$ & $65.7 \pm 8.8$ & $74.3 \pm 4.4$ & $70.2 \pm 9.3$ & $86.4 \pm 4.7$ & $73.2 \pm 6.0$ \\
WX102 & $83.4 \pm 4.1$ & $72.3 \pm 5.1$ & $87.0 \pm 1.9$ & $101.3 \pm 4.4$ & $100.5 \pm 4.2$ & $88.9 \pm 3.9$ \\
Jasper & $87.5 \pm 3.0$ & $64.2 \pm 7.9$ & $77.7 \pm 2.2$ & $64.7 \pm 7.1$ & $79.9 \pm 3.9$ & $74.8 \pm 4.8$ \\
Southern Stars & $77.8 \pm 3.5$ & $64.4 \pm 8.8$ & $73.1 \pm 6.9$ & $83.9 \pm 2.0$ & $96.4 \pm 6.8$ & $79.1 \pm 5.6$ \\
WX73 & $75.1 \pm 1.6$ & $80.3 \pm 4.8$ & $86.5 \pm 1.2$ & $64.6 \pm 4.9$ & $79.5 \pm 3.4$ & $77.2 \pm 3.2$ \\
WX97 & $69.1 \pm 8.2$ & $59.4 \pm 5.0$ & $86.7 \pm 3.9$ & $60.9 \pm 11.0$ & $90.0 \pm 3.0$ & $73.2 \pm 6.2$ \\
Lady Stephanie & $79.4 \pm 3.8$ & $58.7 \pm 6.7$ & $64.8 \pm 6.2$ & $53.6 \pm 3.8$ & $60.2 \pm 5.9$ & $63.3 \pm 5.3$ \\
\hline Average fresh weight & $77.8 \pm 4.0$ & $66.1 \pm 5.0$ & $78.0 \pm 3.8$ & $71.4 \pm 6.2$ & $84.0 \pm 6.0$ & $75.5 \pm 5.0$ \\
\hline
\end{tabular}

LSD for cultivars $=6.8$ days, for vase solution $=3.8$ days and for cultivars $\times$ vase solution $=15.3$ days by analysis of variation at $p=0.05 ; \pm-$ standard errors of the mean

significantly $(\mathrm{p}=0.05)$ increased the vase life of 'WX87' by 1.7 -fold compared to 1.3 -fold in vase solutions of HQS or sucrose, HQS and STS and 1.0fold over the vase solution of sucrose and HQS.

\section{Relationship between the vase life of flowers and leaves}

Leaf vase life for all cultivars in the DI water, except for three out of four cultivars of C. uncinatum and two out of three Verticordia hybrids, exceeded flower vase life by an average of 5.0 days. In addition, the leaf vase life of C. megalopetalum $\times$ C. uncinatum hybrids exceeded the vase life of the flowers by an average of $44 \%$ or 8.0 days. The leaf vase life of three out of four $C$. uncinatum cultivars was $13 \%$ less than their flower vase life, with only 'Purple Pride' having a leaf vase life that was 2.0 days longer than its flower vase life (Figs 2 and 3). The leaf vase life of cultivars with $C$. sp. Gingin as a parent in DI water was longer, with a 1.8-fold increase over their flower vase life, followed by cultivars with $C$. megalopetalum as a parent, with 1.5-fold. Leaf vase life of cultivars with Verticordia as a parent in DI water was greater, with a 1.5 -fold increase for 'Jasper' and 'WX73' and 13\% less for 'Southern Stars' than the flower vase life and with a 1.2-fold increase for C. floriferum hybrid. The leaf vase life of the cultivars was similar to their flower vase life in vase solutions of HQS or HQS and STS, but was significantly $(\mathrm{p}=0.05)-54 \%$ and $17 \%$ - shorter in vase solutions of sucrose and HQS or sucrose, HQS and STS (Figs 2 and 3).

\section{The relationship between flower vase life, stem fresh weight and day for when stem fresh weight reached $75 \%$ of initial weight}

The percentage of fresh weight at the end of vase life was on average $75.5 \pm 5 \%$ over all of the cultivars and vase solutions. In vase solution of HQS there was a significant $(\mathrm{p}=0.05)$ decrease $-9 \%$ on average - of fresh weight at the end of vase life compared to that in DI water. However, for other vase solutions no difference occurred in the average fresh weight at the end of vase life for all cultivars compared to the DI water controls. On average for all cultivars, only those in the vase solution containing HQS had a significantly ( $p=$ 0.05 ) lower fresh weight of $15 \%$ than those in DI water and other vase solutions. 'Southern Stars', 'Denmark Pearl', 'Matilda', 'Bridal Pearl', 'Lady Stephanie', 'Jasper', 'WX102', 'WX97', 'Mullering Brook' and 'Purple Pride' in vase solution of HQS reached the end of their vase life at $42.7 \%$, which was significantly $(\mathrm{p}=0.05)$ lower than in DI water and other vase solutions, with an average of $68.4 \%$, while 'WX102' in vase solutions of sucrose, HQS and STS reached its end of vase life at a significantly $(p=0.05)$ higher percentage of fresh weight than in 
the DI control, HQS or sucrose and HQS, as did 'Laura Mae Pearl' in the vase solution of sucrose and HQS. Across all of the vase solutions, cultivars of Crystal Pearl, Denmark Pearl, Matilda, Lady Stephanie, Mullering Brook and Purple Pride reached the end of their vase life at an average of $67.9 \%$ fresh weight, which was significantly $(\mathrm{p}=$ 0.05) lower than that of 'Southern Stars', 'Bridal Pearl', 'WX73' and 'WX17', with an average of $80.3 \%$, and was also significantly $(\mathrm{p}=0.05)$ lower than that of 'Laura Mae Pearl' and 'WX102', with an average fresh weight of $91.0 \%$ (Tab. 2).

\section{DISCUSSION}

\section{Effect of genotype}

Variation in vase life among cultivars was not always dependent on the particular genetic background of the cultivar, although cultivars solely with C. uncinatum in their genotype tended to have a shorter vase life than cultivars with C. megalopetalum or a different species such as $V$. plumosa. This appears to be dependent on the ability of the genotypes to maintain water balance. Symptoms associated with the end of vase life in Anthurium cultivars are typical of water stress when the balance between water loss and water uptake exceed 1.5 (Mujaffar and Sankat 2003). Similarly, in cut waxflowers the ability to maintain a positive water balance in cut stems determined vase life as found in Anthurium andraeanum Hort., where flowers with a longer vase life had a greater ability to maintain a positive water balance, which appears to be an inherited trait (Elibox and Umaharan 2010). The short vase life of $C$. uncinatum cultivars is consistent to findings reported by Joyce and Jones (1992) and Seaton et al. (2010) and was attributed to a greater water loss in leaves than in flowers, decreasing water potential in leaves (Joyce and Jones 1992). The longer vase life of leaves compared to flowers of C. megalopetalum and $C$. sp. Gingin is similar to the results obtained for Verticordia flowers (Seaton 2006a) and may indicate that leaves dry out more slowly than flowers and do not compete with flowers for water reducing flower vase life. Observations (data not included) showed that 'Lady Stephanie' and 'WX97' had shorter leaves than the $C$. uncinatum cultivars, but longer than C. megalopetalum hybrids, possibly prompting greater water loss. Accordingly, 'Lady Stephanie' and 'WX97' had a longer flower vase life than C. uncinatum cultivars but shorter flower vase life than cultivars with $C$. megalopetalum as a parent. The variation in the vase life of waxflower genotypes was consistent with the findings on Verticordia (Seaton 2006a), Asiatic hybrid Lilium (van der Meulen-Muisers et al. 1999), Dianthus caryophyllus (Downs 1988, Olley 1996) and Antirrhinum majus (Weber et al. 2005). In addition, the flower vase life of 'Southern Stars' (long vase life) at 2.2 times the vase life of 'WX73' (short vase life) was consistent with differences in the parents of these cultivars, where V. plumosa flowers and leaves had two to three times the length of vase life than $V$. grandis (Seaton 2006a).

\section{Effect of vase solutions}

The ability of sucrose to improve water balance (Halevy and Mayak 1974, Kuiper et al. 1995) may have been a critical factor in improving the vase life of the waxflower cultivars used in this study, where flowers with a longer vase life dehydrated slower with sugar present in the vase solution. The different responses of waxflower cultivars to sucrose may indicate a different sensitivity of the cultivars to sucrose, as lower concentrations prolonged the vase life of gladiolus florets by increasing water uptake, whereas higher concentrations seemed to impede water uptake (Bravdo et al. 1974). As sucrose was more effective when HQS was added (Ichimura et al. 1999), suggesting that sucrose may encourage microbial blockage of stems, limiting water uptake. A significant increase in the vase life of $C$. uncinatum cultivars when treated with sucrose and HQS was similar to the result for 'Purple Pride' and 'Alba' (Joyce and Jones 1992). HQS acts an antimicrobial agent (Ketsa et al. 1995), resulting in an increased water uptake of cut flowers (Reddy et al. 1996). HQS at $200 \mathrm{mg} \mathrm{L}^{-1}$ in vase water prolonged the flower vase life of cut snapdragon (Asrar 2012) and rose (Ichimura et al. 1999). However, in this study HQS was ineffective in extending the vase life of waxflowers, which is supported by the results of van Doorn et al. (1990) and Liao et al. (2000), and also shortened leaf vase life, which could be caused by HQS being toxic. The reduction in leaf vase life of some cultivars treated with sucrose and HQS may indicate that concentrations of HQS were toxic to some cultivars, especially their leaves. Sucrose at $58.48 \mathrm{mmol}$ may also have been toxic to some cultivars, as Joyce (1993) found that high sucrose concentrations (i.e. $146.2 \mathrm{mmol}$ ) may cause leaf tip injury through osmotic stress of sucrose accumulation. Also in this study, sucrose at $58.48 \mathrm{mmol}$ caused leaf tip injury in 'Purple Pride' and desiccated the leaves of the 
C. megapetalum hybrids. This indicates the leaves of 'Purple Pride' experienced more turgor loss than leaves of the C. megapetalum hybrids. Variation in the leaf vase life of waxflowers caused by genotypic variance was consistent with the finding on Protea neriifolia where pulsing with $584.8 \mathrm{mmol}$ sucrose $\left(24 \mathrm{~h}, 25^{\circ} \mathrm{C}\right)$ significantly reduced leaf blackening in Protea neriifolia (McConchie and Lang 1993), but not for Protea 'Sylvia' (Stephens et al. 2011). STS was more effective in prolonging the vase life of leaves than the flowers of waxflowers, with leaf vase life significantly increased with the presence of STS in the HQS vase solution, suggesting that STS can reduce the deleterious effect of HQS. STS prevents ethylene induced abscission (Serek and Sisler 2001) and was very effective in preventing flower abscission of C. megalopectalum hybrids (Seaton 2005) and C. uncinatum cultivars (Joyce 1993), but was ineffective in increasing the vase life of cut C. uncinatum (Joyce 1988). STS combined with sucrose and HQS was more effective than sucrose and HQS in terms of increasing the vase life of cut waxflowers, which is supported by a study on cut rose (Liao et al. 2000). This may be due to the role of STS as an ethylene blocker (Joyce 1988) delaying the senescence of ethylene-sensitive flowers (Veen 1983, Knee 1995) and inhibiting the microbial population, which causes vascular occlusion of the stems (Asrar 2012).

\section{CONCLUSIONS}

1. The influence of genotype caused a variation in the vase life of waxflowers, with the shortest vase life found for the cultivars of $C$. uncinatum and the longest vase life found for the cultivars that had C. megalopetalum or Verticordia as a parent.

2. The vase life of waxflower cultivars responded differently to vase solutions.

3. Vase solutions containing HQS, sugar and STS were effective in improving water balance and vase life. However, vase solutions with only HQS or HQS coupled with STS were ineffective in prolonging vase life.

4. The vase life of waxflower cultivars ended when stem fresh weigh reached $75 \%$.

\section{ACKNOWLEDGEMENTS}

Technical support from Mr George and Mr Kris (DAFWA) in collecting samples was acknowledged.

\section{FUNDING}

This work was funded by the Australian Government Overseas Aid Program (AusAID) in 2011 and the support of the Department of Agriculture and Food Western Australia (DAFWA) for its facilities.

\section{AUTHOR CONTRIBUTION}

All authors contributed extensively to the work presented in this paper. C.D.D. conducted the research work, collected and analysed data and wrote the research work; K.S. designed the experiments, provided the samples, gave suggestions and corrected the manuscript; Z.S. gave suggestions and corrected the manuscript.

\section{CONFLICT OF INTEREST}

The authors declare no conflicts of interests.

\section{REFERENCES}

ASRAR A.W.A., 2012. Effects of some preservative solutions on vase-vase life and keeping quality of snapdragon (Antirrhinum majus L.) cut flowers. J. Saudi Soc. Agric. Sci. 11: 29-35.

Beura S., Ranvir S., Sing R., 2011. Effect of sucrose pulsing before storage on postharvest life of Gladiolus. J. Ornam. Hortic. 4: 91-94.

Bravdo B., Mayak S., Gravrieli Y., 1974. Sucrose and water uptake from concentrated sucrose solutions by gladiolus shoots and the effect of these treatments on floret life. Can. J. Bot. 52: 1271-1281.

Dineshbabu M., Jahaharlal M., Vijayakumar M., 2002. Influence of holding solutions on the postharvest life of Dendrobium hybrid Sonia. South Indian Hortic. 50: 451-457.

Downs C.G., 1988. Bud-opening treatments to improve Gypsophila quality after transport. Sci. Hortic. 34: 301-310.

Eason J.R., Morgan E.R., Mullan A.C., Burge G.K., 2001. Postharvest characteristics of Santonia 'Golden Lights' a new hybrid cut flower from Sandersonia aurantiaca $\times$ Littonia modesta. Postharvest Biol. Technol. 22: 93-97.

Elibox W., Umaharan P., 2010. Cultivar differences in the deterioration of vase-vase life in cut-flowers of Anthurium andraeanum is determined by mechanisms that regulate water uptake. Sci. Hortic. 124: 102-108.

Halevy A.H., MayaK S., 1974. Improvement of cut flower quality opening and longevity by preshipment treatments. Acta Hortic. 44: 335-347.

Ichimura K., Kojima K., Gото R., 1999. Effects of temperature, 8-hydroxyquinoline sulphate and sucrose on the vase-vase life of cut rose flowers. Postharvest Biol. Technol. 15: 33-40. 
Jong J.D., Garretsn F., 1985. Genetic analysis of cut flower longevity in Gerbera. Euphytica 34: 779-784.

JoyCE D.C., 1988. Posthavest characteristics of Geraldton wax flowers. J. Am. Soc. Hortic. Sci. 113: 738-742.

Joyce D.C., 1993. Posthavest floral fall in Geraldton wax flower (Chamelaucium uncinatum Schauer). Aust. J. Exp. Agric. 33: 481-487.

Joyce D.C., Jones P.N., 1992. Water balance of the foliage of cut Geraldton waxflower. Postharvest Biol. Technol. 2: 31-39.

Kende H., 1993. Ethylene biosynthesis. Plant Physiol. 44: 283-307.

Ketsa S., Piyasaengthong Y., Prathuangwong S., 1995. Mode of action of $\mathrm{AgNO}_{3}$ in maximizing vase-vase life of Dendrobium 'Pompadour' flowers. Postharvest Biol. Technol. 5: 109-117.

KNEE M., 1995. Copper reverses silver inhibition of flower senescence in Petunia hybrida. Postharvest Biol. Technol. 6: 121-128.

Kuiper D., Ribot S., Van Reenen H.S., Marissen N., 1995. The effect of sucrose on the flower bud opening of 'Madelon' cut roses. Sci. Hortic. 60: 325-336.

Liao L.J., Lin Y.H., Huang K.L., Chen W.S., Cheng Y.M., 2000. Postharvest life of cut rose flowers as affected by silver thiosulfate and sucrose. Bot. Bull. Academia Sinica 41: 299-303.

Macnish A.J., Leonard R.T., Borda A.M., Nell T.A., 2010. Genotypic variation in the postharvest performance and ethylene sensitivity of cut rose flowers. HortSci. 45: 790-796.

McConchie R., LAng N.S., 1993. Carbohydrate metabolism and possible mechanisms of leaf blackening in Protea neriifolia under dark postharvest conditions. J. Am. Soc. Hort. Sci. 118: 355-361.

Morgan E.R., Burge G.K., Seelye J.F., Hopping M.E., Grant J.E., Warren A.G.F., Brundell D.J., 2000. Wide crosses in the Colchicaceae: Sandersonia aurantiaca $\times$ Littonia Modesta. Exp. Cell Res. 121: 343-348.

Mujaffar S., Sankat C.K., 2003. Effect of waxing on the water balance and keeping qualities of cut anthuriums. Int. Agrophys. 17: 77-84.

Olley C.M., 1996. Changes in sugar, protein, respiration, and ethylene in developing and harvested Geraldton waxflower (Chamelaucium uncinatum) flowers. New Zealand J. Crop Hortic. Sci. 24: 143-150.

Onozaki T., Ikeda H., Yamaguchi T., 2001. Genetic improvement of vase-vase life of carnation flowers by crossing and selection. Sci. Hortic. 87: 107-120.

Pun U.K., IchimurA K., 2003. Role of sugars in senescence and biosynthesis of ethylene in cut flowers. JARQ 37: 219-244.

Reddy B.S., Singh K., Singh A., 1996. Effect of sucrose, citric acid and 8-hydroxyquinoline sulphate on the postharvest physiology of tuberose cv. single. Adv. Agric. Res. India 3: 161-167.
SEATON K., 2005. Postharvest treatments for ensuring quality and variety protection of Waxflower on export markets. Horticulture Workshop. Available online at http://agweb.agric.wa.gov.au/Industry dev/hort_ind_Dev/workshop/2005/Seaton.pdf; cited on 2 Dec 2013 .

Seaton K., 2006a. Comparision of vase-vase life and ethylene response of Verticordia cut fowers. J. Hortic. Sci. Biotechnol. 81: 721-727.

Seaton K., 2006b. New developments in postharvest. In Waxflower Conf., 16-17 March, Technology Park, Perth, Western Australia.

Seaton K., Joyce D.C., 1996. Effect of postharvest dipping in insecticides on the vase-vase life of Geraldton waxflower. Aust. J. Exp. Agric. 36: 373-378.

Seaton K., Lee K., Tan B., 2010. Vase life and root propagation of Geraldton wax (Chamelaucium spp.) cut flowers treated with Glyphosate. Korean Soc. Hortic. Sci. 51: 545-550.

Seaton K., Poulish N., 2010. Production of premium waxflower. Department of Agriculture and Food, Western Australia. Bull.: 4778.

Serek M., Sisler E.C., 2001. Efficacy of inhibitors of ethylene binding in improvement of the postharvest characteristics of potted flowering plants. Postharvest Biol. Technol. 23: 161-166.

Stephens I.A., Jacobs G., Holcroft D.M., 2011. Glucose prevents leaf blackening in 'Sylvia' proteas. Postharvest Biol. Technol. 23: 237-240.

TESI R., 1978. Variation of some characters of flowers in clones of Gerbera jamesonii hybrida. L. In: Genetics and Breeding of Carnation and Gerbera. L. Quagliotti and A. Baldi (eds), Proc. Eucarpia Mtg., 24-28 April, Alassio, Eucarpia Mtg, Alassio, Italy: 227-232.

van der Meulen-Muisers J.J.M., Van Oeveren J.C., JANSEN J., van TuYl J.M., 1999. Genetic analysis of postharvest flower longevity in Asiatic hybrid lilies. Euphytica. 107: 149-157.

van Doorn W.G., De Witte Y., Perik R.R.J., 1990. Effect of antimicrobial compounds on the number of bacteria in stems of cut rose flowers. J. Appl. Microbiol. 68: 117-122.

VEEN H., 1983. Silver thiosulphate: an experimental tool in plant science. Sci. Hortic. 20: 211-224.

Weber J.A., Martin W.J., Stimart D.P., 2005. Genetics of postharvest longevity and quality traits in late generation cross of Antirrhinum majus L. J. Am. Soc. Hort. Sci. 130: 694-699.

Woltering E.J., Somhorst D., De Beer C.A., 1993. Roles of ethylene production and sensitivity in senescence of carnation ower (Dianthus caryophyllus) cultivars white sim, chinera and epomeo. J. Plant Physiol. 141: 329-335.

Received November 22, 2015; accepted March 1, 2016 